\title{
AS CONSTRUÇÕES DE DESLOCAMENTO À ESQUERDA DE SUJEITO NO PORTUGUÊS CARIOCA: UM ESTUDO DE TENDÊNCIA
}

\author{
LEFT-DISLOCATED SUBJECTS IN THE PORTUGUESE FROM RIO DE JANEIRO: \\ A TREND STUDY
}

\author{
Mayara Nicolau de Paula \\ Doutoranda em Língua Portuguesa pela \\ Universidade Federal do Rio de Janeiro \\ maynicolau@gmail.com
}

RESUMO: Este artigo apresenta um estudo em "tempo real de curta duração" (cf. LABOV, 1994) da construção de tópico marcado denominada Deslocamento à Esquerda de Sujeito (DE sujeito) no Português Brasileiro (PB), tendo como aporte teórico o modelo de estudo da mudança proposto por Weinreich, Labov e Herzog (2006 [1968]) associado ao modelo de Princípios e Parâmetros (CHOMSKY, 1981). Tais construções se caracterizam por estabelecer uma relação de correferencialidade entre o tópico, termo sobre o qual se faz uma declaração, e o sujeito da oração comentário, como no exemplo: A jaguatirica adulta $_{i}$, ela $a_{i}$ é pequena. Nossa análise é baseada em duas amostras da comunidade de fala do Rio de Janeiro, gravadas nos anos 1980 e em 2000 pelo projeto de pesquisa PEUL-UFRJ. Nosso objetivo principal é refinar a análise das referidas estruturas, visto serem elas uma evidência do "encaixamento" da mudança na representação do sujeito pronominal, conforme evidencia o trabalho de Duarte (1995). O estudo dessas estruturas visa também a contribuir para a discussão sobre a possível inclusão do PB no grupo de línguas com proeminência de tópico e sujeito, segundo a tipologia proposta por Li e Thompson (1976).

PALAVRAS-CHAVE: Tópico marcado; Deslocamento à esquerda de sujeito; Mudança linguística; Estudo em tempo real de curta duração.

ABSTRACT: This paper presents a short-term real-time study (cf. LABOV, 1994) of the topic construction called "left-dislocated subject" in Brazilian Portuguese, associating the theoretical model for the study of language change proposed by Weinreich, Labov and Herzog (2006 [1968]) and the Theory of Principles and Parameters (CHOMSKY, 1981). Such constructions are characterized by establishing a relationship between a topic, external to the sentence, and the subject of the sentence, as in "The adult ocelot it ${ }_{i}$ is small". Our analysis is based on two samples of the speech community of Rio de Janeiro, recorded in the early 1980s and in 2000, by the research project PEUL UFRJ. Our main purpose is to refine the analysis of such structures, since they are considered an evidence of the embedding of the change in the representation of the pronominal subject, as suggested by Duarte (1995). The results of such structures also contribute to the discussion about the possible inclusion of Brazilian Portuguese in the group of "subject and topic-oriented" languages, according to Li \& Thompson's (1976) typology.

KEYWORDS: Marked topics; Left-dislocated subjects; Language change; Short-term real-time study. 


\section{INTRODUÇÃO}

As estruturas de tópico marcado, termo utilizado por Brito, Duarte e Matos (2003), ganharam visibilidade nos estudos linguísticos a partir do artigo de Li e Thompson (1976), tendo despertado o interesse dos linguistas brasileiros a partir dos anos 1980, graças ao trabalho pioneiro de Pontes (1987). As construções se caracterizam por apresentar um sintagma na periferia esquerda da sentença sobre o qual se faz uma proposição, a que chamamos de sentença-comentário.

Apesar de no português brasileiro (PB) se encontrarem quatro estratégias distintas de construção de tópico marcado: anacoluto ou tópico pendente, topicalização, deslocamento à esquerda e tópico-sujeito, este estudo focaliza exclusivamente a construção que apresenta um tópico (nominal ou pronominal) na periferia esquerda da sentença retomado por um elemento corrreferente na posição de sujeito do comentário (doravante DE sujeito), como verificamos nos exemplos a seguir:

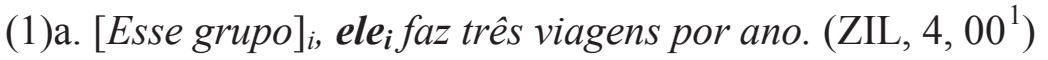

b. $[\text { O Brasil }]_{i}$, veja bem, ele $_{\boldsymbol{i}}$ começou a ser migrado por baixo. (TAD, 4,00)

c. $[E u]_{i}$, antes de entrá pra escola, eu $\boldsymbol{u}_{i}$ fui alfabetizado. (FLA, 3, 00)

As construções de DE sujeito foram apontadas por Duarte (1995) como evidência do "encaixamento" da mudança na representação do sujeito pronominal no PB. Isso se explica pelo fato de que essas estruturas estão ausentes em línguas positivamente marcadas em relação ao Parâmetro do Sujeito Nulo (doravante PSN) e, conforme nos mostra o referido estudo, o PB estaria passando de língua [+ sujeito nulo] para [- sujeito nulo], no que diz respeito aos sujeitos referenciais. Desse modo, entendemos que, já que uma mudança linguística nunca acontece isoladamente no sistema, havendo sempre "efeitos colaterais" (cf. WEINREICH; LABOV; HERZOG (2006 [1968]), as estruturas de DE sujeito são reflexos da mudança na remarcação do valor de PSN, pois, nas línguas românicas de sujeito nulo, como o italiano, o espanhol e o português europeu, uma estrutura de DE, com um pronome na periferia e um na posição de sujeito, não é uma estrutura atestada (exceto, naturalmente, em caso de hesitação).

Nosso objetivo é refinar a análise do elemento que pode ocupar a posição de tópico, a fim de, em uma perspectiva interlinguística, incrementar a discussão em torno do status do PB no que se refere à tipologia das línguas proposta por Li e Thompson (1976). A hipótese que norteia esta análise é a de que pronomes pessoais e SNs, definidos ou não, com o traço semântico [+/-animado], podem ocorrer na posição de tópico e podem ser retomados por um pronome nominativo ou outro $\mathrm{SN}$; além disso, a estrutura, embora preferencialmente encontrada em contextos-raiz, pode aparecer em orações encaixadas, o que indicaria a ausência de restrição à sua ocorrência.

Este artigo está organizado da seguinte maneira: na Seção 1, são apresentados os pressupostos teóricos e a metodologia utilizados na pesquisa; na Seção 2, temos um breve resumo de trabalhos anteriores sobre o tema; na Seção 3, estão os resultados

\footnotetext{
${ }^{1}$ A identificação dos exemplos retirados da amostra utilizada neste trabalho será feita da seguinte maneira: identificação do informante, faixa etária e ano da entrevista.
} 
encontrados e algumas reflexões sobre o que eles significam e, por fim, na última seção estão algumas considerações finais sobre o assunto estudado.

\section{PRESSUPOSTOS TEÓRICOS E METODOLOGIA}

Para investigar o comportamento das construções de DE sujeito no $\mathrm{PB}$, tomamos como aporte teórico o modelo de estudo da mudança proposto por Weinreich, Labov e Herzog (2006 [1968]) no que tange a algumas das questões levantadas por eles, como as "restrições" e o "encaixamento". Associado ao modelo de estudo da mudança, adotamos uma teoria linguística, indispensável à execução de uma pesquisa sociolinguística, no presente caso, o modelo de Princípios e Parâmetros (CHOMSKY, 1981), uma vez que nossa preocupação é observar a mudança em curso no $\mathrm{PB}$ e o aparecimento de estruturas que possam ser consideradas subprodutos dessa mudança.

Como tipologia linguística, adotamos Li e Thompson (1976), que propõem quatro tipos de línguas, que se distinguem segundo o predomínio da orientação (ou estruturação sintática mais recorrente): sujeito - predicado ou tópico - comentário. Algumas apresentam proeminência de sujeito; outras, proeminência de tópico; algumas apresentam proeminência de tópico e sujeito; e outras não apresentam proeminência nem de tópico nem de sujeito.

Nesta análise sobre as construções de DE sujeito, será desenvolvido um estudo em Tempo Real de Curta Duração, conforme propõe Labov (1994). Esse modelo de estudo se divide em Estudo de Painel e Estudo de Tendência, o primeiro focalizando o comportamento do mesmo indivíduo em duas sincronias; o segundo, cujos resultados serão apresentados no presente artigo, consiste na análise de amostras aleatórias da mesma comunidade de fala, estratificadas segundo as mesmas variáveis sociais em dois períodos de tempo.

A amostra utilizada neste trabalho é composta por entrevistas sociolinguísticas do acervo do Projeto PEUL ${ }^{2}$ (Programa de Estudos Sobre o Uso da Língua - UFRJ). Os informantes são do Rio de Janeiro e não possuem nível superior completo de escolaridade, caracterizando-se como uma amostra de fala popular (em oposição ao que se tem entendido como "fala culta", para referência aos indivíduos com curso universitário completo). As entrevistas contemplam gênero, faixa etária (7-14 anos; 1525 anos; 26-49 anos e acima de 50 anos) e número de anos de frequência escolar (5-8; 9-11 ou mais de 11 anos de estudo). O banco de dados do projeto disponibiliza três grandes amostras de fala; a amostra Censo, composta de entrevistas realizadas na década de 1980, e duas amostras posteriores compostas em 2000 (cerca de 19 anos depois), justamente para o estudo da mudança em tempo real de curta duração (LABOV, 1994; PAIVA E DUARTE, 2003). Uma delas é a Amostra Recontato, que, como o nome indica, consiste no estudo da fala do mesmo indivíduo gravado nos anos 1980, permitindo o Estudo de Painel, e a outra é uma nova amostra da mesma comunidade de fala, utilizada para o que Labov se refere como Estudo de Tendência. Aqui nos concentramos no Estudo de Tendência, para o qual utilizamos vinte informantes vindos da amostra dos anos 1980 e outros vinte retirados da amostra 2000.

\footnotetext{
${ }^{2}$ www.letras.ufrj.br/peul
} 
O levantamento dos grupos de fatores a serem considerados na análise foi feito com base (a) em estudos anteriores sobre as construções de tópico no PB (PONTES, 1987; ORSINI, 2003; VASCO, 2006) e (b) na hierarquia de referencialidade proposta por Cyrino, Duarte e Kato apresentada a seguir:

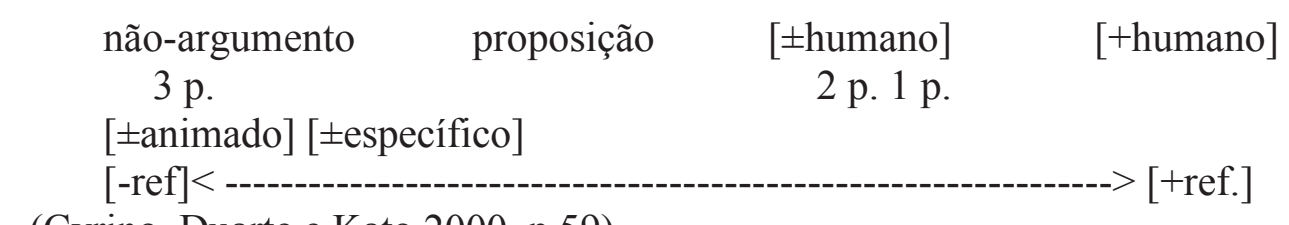

(Cyrino, Duarte e Kato 2000, p.59)

Os grupos de natureza linguística foram estabelecidos, principalmente, no sentido de oferecer uma caracterização (i) do tipo de elemento que pode ocupar a posição de tópico (se um pronome, se um SN) além do feixe de traços [+/-animado], [+/- específico]; (ii) da presença ou ausência de material interveniente entre tópico e correferente; e (iii) do contexto sintático em que ocorre a estrutura de DE sujeito (configuração sintática da estrutura em que ocorrem tópico e correferente).

Os dados deste trabalho foram coletados e codificados seguindo os passos da metodologia variacionista (cf. GUY; ZILLES, 2007) e submetidos ao programa Goldvarb 2001 para a contagem geral, distribuição e cruzamento. Não empreendemos uma análise com base em pesos relativos porque a escolha entre DE sujeito com tópico representado por um SN ou por um pronome não constitui exatamente uma regra variável. Elegemos como variável dependente, apenas para a distribuição dos dados, o fato de a posição de tópico ser ocupada ou por um pronome ou por um sintagma nominal. No que tange aos tópicos pronominais, estes podem ser preenchidos por um elemento nominativo ou demonstrativo.

\section{AS CONSTRUÇÕES DE DESLOCAMENTO DE SUJEITO NAS LÍNGUAS ROMÂNICAS}

Trabalhos feitos anteriormente (PONTES, 1987; VASCO, 1999, 2006; ORSINI, 2003; VASCO; ORSINI, 2007) apontam para o fato de que o PB não se comporta como uma língua prototípica de proeminência de sujeito, mas se apresenta como um sistema misto, com proeminência de sujeito e de tópico. As estruturas de DE sujeito no PB analisadas aqui servem como evidência dessa mudança de comportamento, já que as informações que encontramos na literatura apontam grandes restrições a tais construções em línguas românicas de sujeito nulo, como o português europeu, o italiano e o espanhol. Ainda na comparação com as línguas do grupo românico, observamos que o PB apresenta algumas semelhanças com o francês no caso das construções de DE sujeito. Esse assunto será retomado mais adiante.

No português europeu (PE), assim como nas outras línguas românicas de sujeito nulo, as construções de DE sujeito não são atestadas. Em relação ao italiano Ochs e Duranti (1979) apud Duarte (1995) assinalam, com base em análise de dados, que não existem construções de DE sujeito. Segundo os autores, todos os elementos deslocados são coindexados com clíticos, ou seja, trata-se de um deslocamento à esquerda clítico, em que o tópico retoma um complemento. A ausência de DE sujeito é explicada pelos autores pelo fato de o italiano ter como default o sujeito nulo, graças à rica flexão 
verbal. Apenas quando o sujeito merece ênfase ou contraste, o pronome é pronunciado. Em outras palavras: "duplicar" um sujeito seria incompatível com um sistema que tende a apagar um pronome sujeito, exceto se sua ausência produzir ambiguidade.

O trabalho de Rivero (1980) apud Duarte (1995) para o espanhol revela que DE só é atestado em estruturas de deslocamento à esquerda clítico, como em (2a). A construção de DE sujeito pode ocorrer desde que o pronome receba ênfase, isto é, quando numa construção com valor contrastivo (cf. RIVERO, 1980: 363, apud DUARTE, 1995) como em (2b).

(2)a. [Al partido carlista $]_{i}$, dicen que no lo legalizaron para las elecciones.

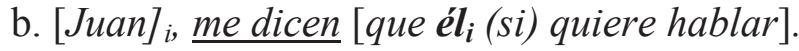

No PE, ocorre exatamente o mesmo que no espanhol e no italiano: tal como em (2a), temos o deslocamento à esquerda clítico, ilustrado em (3a-b), a seguir. Da mesma forma, tal como em (2b), podemos ver (3c), que ilustra o deslocamento à esquerda do sujeito, que só é possível porque não há adjacência sintática entre tópico e sujeito (cf. BRITO; DUARTE; MATOS 2003 p. 493-495):

(3)a. Disseram-me [que [ao João], não lhe $\boldsymbol{i}_{i}$ pagaram o ordenado desse mês].

b. [Os gerentes], trata-os ${ }_{i}$ como se fossem míseros contínuos.

c. [O João $]_{i}$... [ ouvi dizer [que ele tinha ido passar férias a Honolulu.

Para o francês, por outro lado, um sistema de sujeitos expressos obrigatoriamente, Barnes (1986) aponta que $81 \%$ dos casos de DE, obtidos em um corpus oral, foram referentes justamente à retomada do sujeito. Segundo a autora, a construção de DE sujeito mais comum é aquela em que o tópico e o sujeito são de primeira pessoa $(69 \%$ dentro da classe dos deslocamentos com pronome). Trata-se de estruturas estilo: moi je como vemos em (4) (cf. BARNES, 1986 p. 209-220):

\section{(4) $[\mathrm{Moi}]_{i} \boldsymbol{j}_{\boldsymbol{i}}$ bois énormément.}

$\mathrm{Eu}_{\mathrm{i}} \mathbf{e u}_{\mathbf{i}}$ bebo muito.

Nas construções de DE sujeito em que o tópico é um SN lexical, há algumas restrições: o SN tem geralmente o traço [+humano], como mostram (5 a-b). Se o SN é [-humano], em geral a retomada se faz não por um pronome pessoal, mas por um demonstrativo "ce", como vemos em (6 a-b):

(5) a. $[\text { Nancy }]_{i}$ elle $_{\boldsymbol{i}}$ aimerait beaucoup ça.

$\mathrm{Nancy}_{\mathrm{i}}$, ela $\mathrm{i}_{\mathrm{i}}$ adoraria isso.

b. On était oblige, [le mec $]_{i}$ il $_{i} m$ 'a poussée!

Fomos obrigados, o cara ele $_{\mathrm{i}}$ me empurrou!

(6) a. Moi je trouve que [la cuisine $]_{i} \boldsymbol{c}_{\boldsymbol{i}}$ 'est l'endroit le plus important d'une maison.

$\mathrm{Eu}$, eu acho que a cozinha $\mathrm{i}_{\mathrm{i}}$ (essa) $)_{\mathrm{i}}$ é a parte mais importante de uma casa.

b. J'avais un philosophe, un type [donc [la matière principale $]_{i} \boldsymbol{c}_{\boldsymbol{i}}$ 'est la philosophie.]

Eu conhecia um filósofo, um cara cujo assunto principal $_{i}$ este $_{i}$ é a filosofia. 
Barnes afirma que DE sujeito no francês não se refere exclusivamente a elementos dados no discurso; pelo contrário, a construção pode introduzir elementos novos sem qualquer função contrastiva; além disso, a pausa entre tópico e sujeito não é obrigatória, isto é, não há entoação específica. As sentenças ocorrem majoritariamente em contexto matriz, porém elas também podem aparecer em contexto encaixado, ainda que com frequência mais baixa, como o exemplo (6b) ilustra.

Publicado 25 anos depois do artigo de Barnes, o trabalho de Avanzi (2011) nos traz informações novas sobre as restrições apontadas no texto de 1986. Trata-se de um estudo prosódico sobre as construções de deslocamento à esquerda de sujeito, baseado em 70 enunciados do francês parisiense. Nosso interesse recai sobre os dados apresentados, que nos permitem rever as informações contidas em Barnes. De fato, pelo que afirma Avanzi, o traço [-animado] não impede a retomada por um pronome pessoal. A restrição parece recair sobre o traço [-específico] (nas palavras do autor, um SN que define uma classe), independentemente do traço de animacidade. Os exemplos em (7), de Avanzi, exibem dados que conferem com os de Barnes:

(7) a. $[\mathrm{moi}]_{\mathrm{i}} \mathrm{je}_{i}$ suis mariée

$[\mathrm{eu}]_{\mathrm{i}}$ eu $\mathrm{i}$ sou casada'

b. $[\text { lui }]_{\mathrm{i}} i_{\mathrm{i}}$ fasait du roller

$[\mathrm{ele}]_{\mathrm{i}}$ ele $_{\mathrm{i}}$ praticava patins (andava de patins, praticava patins, patinava)

c. alors [la plus grande $]_{\mathrm{i}}$ elle $\mathrm{i}_{\mathrm{i}} \mathrm{s}^{\prime}$ apelle Guilaine

então [a mais velha $]_{\mathrm{i}}$ ela $_{\mathrm{i}}$ se chama Guilaine

d. [les petits que j'ai $]_{\mathrm{i}}$ ils $s_{\mathrm{i}}$ sont vraiment très independentes

[as crianças que eu tenho $]_{i}$ elas $_{i}$ são muito independentes

Em (8), vemos, por outro lado, dados que mostram ter havido uma ampliação no uso de DE sujeito, com a diminuição das restrições: tópicos de terceira pessoa, com o traço [humano +específico], em contextos de raiz ou em encaixadas:

(8) a. [l'année universitaire $]_{i}$ ellei $i_{i}$ commence demain

[o ano universitário $]_{i}$ ele $_{i}$ começa amanhã.

b. [les horaires de bac $]_{\mathrm{i}}$ ils $s_{\mathrm{i}}$ sont fixes effectivement

[os horários do $b a c]_{i}$ (vestibular) eles ${ }_{i}$ são rígidos.

c. [tes chaussures de danse $]_{\mathrm{i}}$ elles $\mathrm{i}_{\mathrm{i}}$ ont une particulairité

[teus sapatos de dança $]_{i}$ eles $_{\mathrm{i}}$ têm uma peculiaridade.

d. ce comme ça $[\text { la vie }]_{\mathrm{i}}$ elle $_{\mathrm{i}}$ est dure

é assim mesmo [a vida $]_{i}$ ela ${ }_{i}$ é dura

e. c'est à dire $\left[q u e[\text { ses idées }]_{\mathrm{i}}\right.$ au début $[\text { eles }]_{\mathrm{i}}$ peuvent être três bonnes

isso significa que [suas ideias $]_{\mathrm{i}}$ a princípio elas $\mathrm{s}_{\mathrm{i}}$ podem ser muito boas.

O único contexto de resistência a DE sujeito parece ser o traço [-específico], independentemente do traço [+/-humano]. Veja-se, por exemplo, em (9a), que o SN "les femmes" ("as mulheres" ou "mulheres") tem referência menos específica (ou genérica, isto é, define uma classe), sendo retomado por um demonstrativo "ce", a que o autor se refere como uma forma "intermediária" ou "semilexical"; em (9b) vemos um SN [humano -específico], que sofre a mesma restrição:

(9)a. [les femmes $]_{\mathrm{i}}$ ce $\mathrm{i}_{\mathrm{i}}$ sont toutes des menteuses 
[as mulheres/mulheres] $]_{i}$, essas $_{i}$ são todas mentirosas / [mulheres] $]_{i}$, essas $_{i}$ são umas mentirosas.

b. [Les fruits $]_{\mathrm{i}}$ ça $a_{\mathrm{i}}$ se mange sans faim

[as frutas/frutas $]_{i} \operatorname{essas}_{i}$ se come(m) sem fome.

Além da não obrigatoriedade de pausa, Avanzi mostra que, desde que com traços específicos, a construção de DE pode aparecer em contextos raiz ou encaixados, como, aliás, já apontava Barnes:

\section{(10) Je crois [que [Michel] il $_{i}$ il'a perdue ma bague de fiançailles} eu acho que $[\mathrm{o} \text { Michel }]_{\mathrm{i}}$ ele $_{\mathrm{i}}$ perdeu a minha aliança de noivado

Em resumo, o francês parece ter perdido restrição à animacidade para a retomada pronominal, mas mantém a restrição ao traço [-específico]. Tais restrições, conforme constataremos na próxima seção, não estão presentes do PB nem nos anos 1980 nem em 2000 .

Em se tratando do PB, no trabalho de Eunice Pontes publicado em 1987, a construção de $\mathrm{DE}$ sujeito já era apontada e, pelos exemplos da autora, não parecia haver restrição à animacidade do tópico. Entretanto, não se mencionava a combinação pronome (na posição de tópico) + pronome (na posição de sujeito). Até o trabalho de Duarte (1995), não temos conhecimento dessas estruturas de $\mathrm{DE}$ com um pronome em posição de tópico. A partir daí, são apontadas construções com pronomes fortes (tópicos) e fracos (sujeito) e mostra-se que não há restrição quanto ao SN lexical que ocupa a posição de tópico. Em (11) observamos que o tópico "um trabalho" não apresenta marcas formais de definitude, ou seja, um artigo ou pronome definido, porém está na posição de tópico sem que isso torne a sentença agramatical.

(11) Eu acho que [um trabalho], ele $\boldsymbol{e}_{\boldsymbol{i}}$ teria que começar por aí. (DUARTE,

Seguindo o caminho aberto por Duarte, que aponta a relação entre o preenchimento do sujeito e a construção de DE sujeito, seguem-se os estudos de Vasco (1999; 2006) e Orsini (2003), que analisam o conjunto de construções de tópico marcado e destacam que DE está concentrada na função de sujeito seja o elemento periférico um pronome, seja um SN lexical.

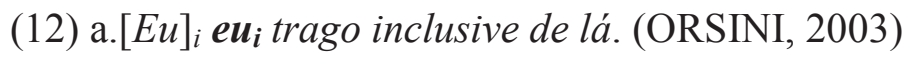

b. [o cara que estuda letras $]$, pô, na França ele e $_{i}$ ão faz francês e português, entendeu? (VASCO, 2006)

Vasco e Orsini (2007) confrontam os resultados da fala culta e popular para as quatro estratégias de construção de tópico. Considerando o conjunto de construções de tópico marcado, temos uma grande proximidade nos resultados obtidos para o deslocamento à esquerda de sujeito, $55 \%$ na fala culta e $51 \%$ na fala popular e, assim como já havia sido atestado anteriormente, Topicalização de objeto e DE de sujeito estão em distribuição complementar nas duas modalidades de fala. 
Como mostramos nesta seção, as construções de DE sujeito são típicas das línguas românicas de sujeito expresso, como o francês, estando ausentes nas línguas de sujeito nulo, exceto quando não há adjacência sintática, com propósito de ênfase ou contraste. Quanto à sua ocorrência frequente no francês, verificamos que com o tempo as restrições ao traço semântico diminuem. No PB, não parece haver restrições nem quanto ao contexto sintático, nem quanto ao traço semântico.

\section{ANÁLISE DOS DADOS}

Encontramos na amostra analisada 209 dados de DE sujeito na década de 1980 e 143 dados em 2000. A diferença na quantidade de dados, certamente, se deve ao fato de as entrevistas dos anos 1980 serem mais longas do que as feitas em 2000. Contudo, nosso foco não está no aumento do número de ocorrências, mas na possível redução de restrições estruturais para as construções estudadas.

O primeiro resultado a ser avaliado diz respeito ao grupo 'classe gramatical do elemento que ocupa a posição de tópico’. Os resultados estão na tabela a seguir:

Tabela 1 Distribuição percentual dos dados segundo a classe gramatical do tópico

\begin{tabular}{l|l|l|l|l}
\hline & \multicolumn{2}{|l|}{ Anos 1980 } & \multicolumn{2}{l}{ Ano 2000 } \\
\hline Classe gramatical & $\mathbf{N}^{\mathbf{0}}$ de oco & $\mathbf{\%}$ & $\mathbf{N}^{\mathbf{0}}$ de oco & $\mathbf{\%}$ \\
\hline Pronome 1 $^{\mathrm{a}}$ & 67 & 32 & 26 & 19 \\
\hline Pronome 3 $^{\mathrm{a}}$ & 37 & 18 & 16 & 11 \\
\hline Pronome arb $^{3}$ & 13 & 6 & 10 & 7 \\
\hline Pronome dem & 5 & 2 & 3 & 2 \\
\hline SN simples & 77 & 37 & 77 & 54 \\
\hline SN complexo & 10 & 5 & 11 & 7 \\
\hline Total & $\mathbf{2 0 9}$ & $\mathbf{1 0 0}$ & $\mathbf{1 4 3}$ & $\mathbf{1 0 0}$ \\
\hline
\end{tabular}

Antes dos comentários sobre o que nos dizem os resultados, seguem exemplos de cada uma das estratégias encontradas, respectivamente:

(13)a. $[E u]_{i}$, logicamente, isso e $\boldsymbol{e u}_{i}$ não posso dizer pra você. [DAV,3,80]

b. $[E l a]_{i}$, quando a gente começa a querer fazer fisica, ela in $_{i}$ que se pentear. [ERI,1,80]

c. [Você] $]_{i}$ a partir de vinte e nove anos vocé $\hat{\boldsymbol{i}}_{\boldsymbol{i}}$ é considerada velha. [ANa,3,00]

d. [Esse], na primeira ele e $_{i}$ morreu. [JAN,4,80]

e. [Os carros da Globo $]_{i}$, eles e $_{i}$ êm em cima da calçada. [LEI,2,80]

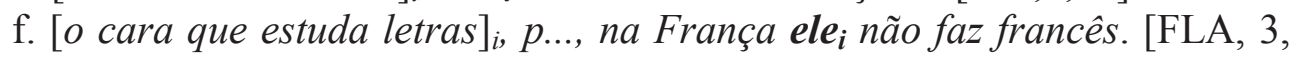
$00]$

As informações fornecidas pela distribuição das ocorrências nos possibilitam pensar sobre uma de nossas hipóteses, a de que o sistema do PB não impõe restrições quanto à natureza do elemento que ocupa a posição de tópico, como já foi verificado por autores como Duarte (1995), Orsini (2003) e Vasco e Orsini (2007). Nos anos 1980, ao

\footnotetext{
${ }^{3}$ Referência arbitrária.
} 
agruparmos todos os tipos de pronome, vemos que a frequência de tópicos pronominais é superior, totalizando $58 \%$ contra $42 \%$ de tópico SN. Dentre os tópicos pronominais, o pronome de primeira pessoa é o mais recorrente. Por outro lado, no ano 2000, os tópicos com SN totalizam 61\%, contra 39\% de tópicos pronominais.

No que diz respeito somente aos tópicos representados por pronomes, em ambas as sincronias, os pronomes de primeira pessoa são os mais frequentes, seguidos pelos de terceira. Os pronomes com referência arbitrária (ou indeterminada) e demonstrativos são os menos frequentes. A diminuição no percentual geral de pronomes de uma sincronia para outra pode, entretanto, se dever a peculiaridades das entrevistas, mas a maior ocorrência de SNs na segunda sincronia nos permitirá investigar bem a nossa hipótese de que o PB não impõe restrições à classe gramatical do tópico.

Sendo assim, os próximos resultados a serem apresentados serão referentes ao grupo 'estrutura interna do tópico SN e seus traços semânticos'. A tabela a seguir apresenta a estrutura interna dos SNs tópicos, destacando os elementos que ocupam a margem esquerda e a margem direita.

Tabela 2 Estrutura interna do SN tópico

\begin{tabular}{|c|c|c|c|c|}
\hline & \multicolumn{2}{|c|}{ Ano 1980} & \multicolumn{2}{|c|}{ Ano 2000} \\
\hline Estrutura interna do SN tópico & $\mathbf{N}^{0}$ oco & $\%$ & $\mathbf{N}^{0}$ oco & $\%$ \\
\hline Determinante ou quantificador + nome & 59 & 67 & 66 & 75 \\
\hline $\begin{array}{l}\text { Determinante ou quantificador }+ \text { nome }+ \text { modificador ou } \\
\text { complemento }\end{array}$ & 23 & 26 & 19 & 21 \\
\hline Nome nu & 5 & 7 & 3 & 4 \\
\hline Total & 87 & 100 & 88 & 100 \\
\hline
\end{tabular}

Os SNs que têm somente a margem esquerda preenchida, por determinante ou quantificador, conforme exemplo (14), são os mais frequentes nos dois períodos, totalizando $67 \%$ na década de 1980 e $75 \%$ em 2000.

(14)a. [O paulista $]_{i}$, ele $_{i}$ fala um pouquinho cum a voz meio fanhosa. [REI, 3, 00]

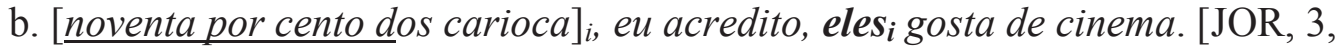
00]

Com percentuais de $26 \%$ e $21 \%$ para cada período respectivamente, encontramos SNs com determinantes à esquerda e modificadores ou complementos à direita. Esses modificadores podem ser SAdjs e SPs simples, como exemplificado em (15 a-b), ou orações relativas (o que chamamos de SN complexo), como mostram as sentenças (15 c-d):

(15)a. [a jaguatirica adulta] ${ }_{i}$, ela $\boldsymbol{a}_{i}$ é pequena. $[\mathrm{LEO}, 2,80]$

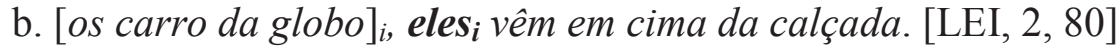

c. [a pessoa que usa muito a voz pra trabalhá], ela deveria fazê um trabalho pra se protegê. [ADR, 2,00]

d. Esses- [essas pessoas que moram aqui na frente $]_{i}$, ela- elas, mais perturbam [JOA, 3, 80] 
Finalmente, em relação aos nomes nus, isto é, sem determinantes ou modificadores, estes aparecem em menor frequência, geralmente no singular ${ }^{4}$ e, geralmente, retomados por SN, como vemos nos exemplos em (16):
(16)a. [Robalo] ${ }_{i}$ é.. Robalo i aqui é comum. [JAN, 4, 80] $80]$

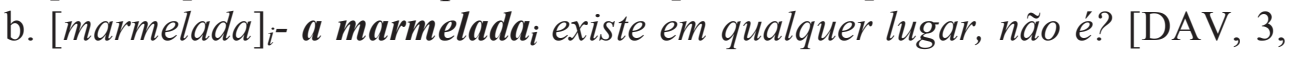

A análise da estrutura do SN revela um dado importante: o fato de aparecerem SNs nus, em geral nomes de referência genérica e novos no contexto discursivo. Isso pode ser um argumento contra o caráter presumivelmente definido do tópico. Trataremos essa baixa restrição como um comportamento que permite classificar o PB como língua mista, já que nesse tipo de língua qualquer sintagma está autorizado a ocupar a periferia esquerda da sentença, sem a necessidade de ser definido ou específico.

Como último grupo de fatores relacionado exclusivamente ao tópico, decidimos associar ao traço semântico [+/- animado], relevante nos estudos pertinentes à trajetória do preenchimento do sujeito, traços relativos à especificidade do $\mathrm{SN}$, tomando como base a hierarquia referencial proposta por Cyrino, Kato e Duarte (2000) já ilustrada anteriormente. Segundo as autoras, num processo de mudança em direção ao preenchimento do sujeito, os itens [+ referencial] e [+ humano], no ponto mais alto da hierarquia (à direita da linha) são os primeiros a se tornarem plenos.

Os pronomes de primeira pessoa bem como os de referência arbitrária, todos com traço inerentemente [+ humano], são excluídos dessa análise. Os pronomes de terceira pessoa foram incluídos neste grupo, visto que se comportam como os SNs por conterem o traço semântico do referente que está sendo retomado no discurso. A Tabela 3 reúne esses resultados:

Tabela 3 Traço semântico e especificidade do tópico

\begin{tabular}{|c|c|c|c|c|c|c|c|c|}
\hline & \multicolumn{4}{|c|}{ Anos 1980} & \multicolumn{4}{|l|}{ Ano 2000} \\
\hline & \multicolumn{2}{|c|}{ SN } & \multicolumn{2}{|c|}{ Pronome $3^{\mathrm{a}}$} & \multicolumn{2}{|l|}{ SN } & \multicolumn{2}{|c|}{ Pronome $3^{a}$} \\
\hline & $\mathrm{N}^{\circ} \mathrm{OCO}$ & $\%$ & $\begin{array}{l}N^{0} \\
\text { OCO }\end{array}$ & $\%$ & $\mathrm{~N}^{\circ} \mathrm{OCO}$ & $\%$ & $\begin{array}{l}\mathrm{N}^{\mathbf{0}} \\
\text { OCO }\end{array}$ & $\%$ \\
\hline +humano +específico & 46 & 54 & 35 & 94 & 49 & 56 & 16 & 100 \\
\hline + humano - específico & 17 & 20 & - & - & 17 & 19 & - & - \\
\hline - humano +específico & 4 & 4 & - & - & - & - & - & - \\
\hline - humano - específico & 3 & 3 & - & - & - & - & - & - \\
\hline - animado +específico & 14 & 16 & - & - & 18 & 20 & - & - \\
\hline - animado - específico & 2 & 2 & 1 & 6 & 4 & 5 & - & - \\
\hline Total & 87 & 100 & 36 & 100 & 88 & 100 & 16 & 100 \\
\hline
\end{tabular}

Os traços levados em consideração na nossa análise permitem seis combinações que nos ofereceram uma análise semântica detalhada do elemento que está na posição de tópico.

Nos dois períodos de tempo, os tópicos nominais se caracterizam por apresentar preferencialmente sintagmas com os traços [+ humano + específico] (54\% e 56\%). São

\footnotetext{
${ }^{4} \mathrm{O}$ PB se distingue das demais línguas românicas por preferir nomes contáveis com referência genérica no singular (cf. MARAFONI, 2010).
} 
nomes próprios, em geral familiares, amigos e personalidades ou nomes comuns, relativos a membros da família, conhecidos, que exibem à esquerda um determinante, como se pode observar nos exemplos. A distribuição percentual nos mostra um comportamento semelhante no que diz respeito a essas estruturas nos dois períodos estudados.

(17) a. porque [Romário $]_{i}$ ele $_{\text {i falô mesmo que ele sai. [SIM, 3, 00] }}$

b. [Meu irmão], na noite de domingo, ele $\boldsymbol{e}_{\boldsymbol{i}}$ vai na missa a noite. [ANA, 3, 00]

c. Inclusive, [essa menina que faz minha unha mesmo $]_{i}$ ela ${ }_{i}$ é assim, na casa dela é assim. [LEI, 2, 80]

No caso dos pronomes de terceira pessoa com os traços [+ humano + específico], podemos observar que são numericamente menos frequentes que os SNs, mas, ainda assim, do conjunto de 35 pronomes na primeira sincronia e 16 na segunda, todos, exceto um caso, têm esses traços, como se vê em (18).

(18)a. [Ele], parece que ele $\boldsymbol{e}_{\boldsymbol{i}}$ sofreu muito quando era pequeno. [JOA,3, 80] (falando do marido)

b. Mas $[\text { ela }]_{i,}$ que nem outro dia, ela mandou a gente não ir pra fora. [ADR, $1,80]$ (falando da professora)

Assim como o fator anterior, os SNs com os traços [+ humano - específico] mantêm suas frequências estáveis nas duas sincronias: 20\% nos anos 1980 e $19 \%$ em 2000. Nesse caso, apesar de o tópico apresentar o traço [+ humano] sua referência é [específica], ou seja, refere-se a grupos ou pessoas indeterminadas, como nos exemplos em (19). Os tópicos desse grupo não devem, entretanto, ser confundidos com os tópicos pronominais de referência arbitrária. Esses últimos não podem ser retomados por um pronome de terceira pessoa:

O cara - ele....

* você - ele...

(19) a. [O carioca $]_{i}$, eu acho que ele fala muito errado. [MAR, 4, 00] $00]$

b. [o cara que, p..., que é mais safo] ele $_{i}$ vai procurá outra coisa. [FLA, 3,

O traço [+ humano] aparece com maior frequência nas duas amostras. Entretanto, temos, nos anos 1980, casos de SNs com os traços [- humano + - específico]. Assim, na década de 1980, há 4\% de tópicos cujo SN é [- humano + específico] e 3\% de tópicos cujo SN é [- humano - específico]. Os tópicos aqui fazem referência a animais, já que optamos por separar [- humano] e [+ - animado]. Os exemplos em (20) apresentam os tópicos com o traço [- humano + específico] e [- humano - específico] respectivamente (a não ocorrência de dados desse tipo em 2000 não significa, pois, que o tópico rejeite esse feixe de traços).

(20)a. [Aquela cachorra $]_{i}$, ali fora, com a gente ela $\boldsymbol{i}_{\boldsymbol{i}}$ é uma... dentro de casa não deixa ninguém entrar. [JOS, 4, 80]

b. [A jaguatirica adulta $]_{i}$, ela $a_{i}$ é pequena, ela não cresce mais do que essa mesa. [LEO, 2, 80] 
O SN tópico com traços [- animado + específico], exemplificado em (21), é menos frequente hierarquicamente nos anos 1980 comparado ao ano 2000, ainda que as frequências sejam muito próximas.

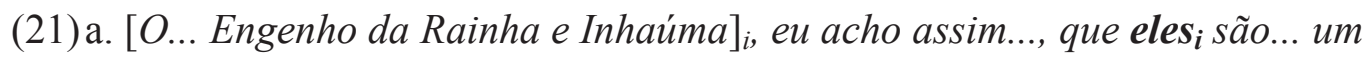
só! [JOA, 4, 00]

b. [Esses passeio que eu faço tudo $]_{i}$ ele $\boldsymbol{e}_{i}$ é de graça. [ZIL, 4, 00]

O SN tópico [- animado - específico] apresenta 2\% nos anos 1980 e 5\% em 2000, sendo, em ambas as sincronias, o feixe de traços menos recorrente. Assinale-se que o tópico [- animado] com referência genérica (exemplo 22a) foi menos recorrente do que o [- animado] com referência específica (exemplo 22b) nos dois períodos analisados. É exatamente com esse conjunto de traços ([- animado - específico]) que temos, nos anos 1980, a única ocorrência de pronome na posição de tópico, como se ilustra em (22c):

(22)a. E [a produção $]_{i}$, quando sendo uma coisa maior, ela $\boldsymbol{i}_{i}$ te exige muito [ADR, 2, 00]

b. [A quadra do meu colégio $]_{i}$, ela já estava para sair há mais de dez anos. [FAT, 2, 80] c. Mas [ela $]_{i}$ crua, ela é $_{\text {enais saudável }}^{5}$. [JAN, 4, 80]

Esse grupo, que envolve aspectos de natureza semântica, nos permite caracterizar, de maneira detalhada, o constituinte que está na posição de tópico. O SN tópico é preferencialmente [+ humano + específico], reunindo 54\% dos dados na década de 1980 e $56 \%$ em $2000^{6}$. A segunda combinação de traços mais recorrente na amostra de 1980 foi [ + humano - específico], enquanto na amostra de 2000 foi [- animado + específico], sendo que o [+ humano - específico] aparece em terceiro lugar com um valor muito próximo (20\% para o primeiro e $19 \%$ para o segundo). Os traços [- humano específico] são os menos frequentes na primeira sincronia e não aparecem na segunda, havendo um menor número de ocorrências, portanto, de DE sujeito.

Os resultados aqui apresentados nos possibilitam concluir que, nos dois períodos estudados, as construções de DE sujeito são mais frequentes com tópicos [+humano +específico], ou seja, esse feixe de traços favorece a manifestação das construções de deslocamento à esquerda de sujeito seja com tópicos $\mathrm{SN}$, seja com tópicos pronominais de terceira pessoa.

Podemos afirmar também que o PB não oferece restrições à construção de DE com o tópico [-humano] e [-animado], podendo ele ser mais ou menos específico; esse último traço (a especificidade) já havia sido comentado na presença de elementos sem determinantes (SNs nus), por exemplo, quando tratamos da estrutura do SN.

Considerando que, em relação ao preenchimento do sujeito, os de terceira pessoa com referente [+humano +específico] foram preenchidos antes daqueles com traço [humano ou - animado] é natural esperar que a frequência das construções de DE sujeito

\footnotetext{
${ }^{5}$ Neste exemplo, o referente é o nome "ostra" conforme se pode verificar num trecho maior da entrevista: "[Põe limão], sim. [(inint)-] ("não falei porque a senhora não") tinha perguntado, mas ("quer) põe um limãozinho na ostra. Mas ela crua, ela é mais saudável."

${ }^{6}$ Consideramos aqui tanto os SNs simples quanto os SNs complexos.
} 
acompanhe a hierarquia de referencialidade dos sujeitos: contextos menos resistentes à implementação do sujeito favoreceram construções de DE sujeito, fazendo com que sua frequência seja elevada; contextos mais resistentes ao preenchimento do sujeito revelarão menos ocorrências de DE sujeito. Os sujeitos com o traço [-animado] e os genéricos são os mais resistentes à mudança em direção ao sujeito pronominal preenchido. Em consequência, a incidência de construções de DE sujeito com o tópico reunindo esses traços são menos frequentes.

Partindo para o grupo que controla a presença versus a ausência de material interveniente, nossos resultados mostram que a presença de material entre o tópico e sua retomada é ligeiramente mais frequente nas duas amostras - 53\% na década de 1980 e $65 \%$ em 2000 (o que significa que, nos dois períodos, a presença de material supera levemente a ausência). Vejamos, na Tabela 4, os resultados para a presença e ausência de material interveniente, distribuídos, no caso de presença, conforme a natureza do material entre tópico e retomada.

Tabela 4 Distribuição da natureza do material interveniente

\begin{tabular}{ll|l|l|l}
\multicolumn{2}{c}{} & \multicolumn{2}{c}{ Anos 1980 } & \multicolumn{2}{c}{ Ano 2000 } \\
\cline { 2 - 5 } & $\mathbf{N}^{\mathbf{0}} \mathbf{0 c o}$ & $\mathbf{\%}$ & $\mathbf{N}^{\mathbf{0}}$ oco & $\mathbf{\%}$ \\
\hline $\begin{array}{l}\text { Ausência de material } \\
\text { interveniente }\end{array}$ & 100 & 47 & 50 & 35 \\
\hline Interrupção $^{7}$ & 15 & 7 & 19 & 13 \\
\hline Marcador discursivo $^{\text {Manyyyy}}$ & 6 & 3 & 11 & 8 \\
\hline Adjuntos adverbiais $^{8}$ & 58 & 28 & 36 & 25 \\
\hline Sintagma oracional & 30 & 15 & 27 & 19 \\
\hline Total & $\mathbf{2 0 9}$ & $\mathbf{1 0 0}$ & $\mathbf{1 4 3}$ & $\mathbf{1 0 0}$ \\
\hline
\end{tabular}

A distribuição percentual do tipo de material interveniente presente, em termos hierárquicos, é muito semelhante nas duas sincronias. Os adjuntos adverbiais são os mais recorrentes tanto nos anos 1980 quanto em 2000, (exemplos em (23)), seguidos dos sintagmas oracionais (exemplos em (24)).

(23)a. mas $[e u]_{i}$ esse ano $\boldsymbol{e u}_{i}$ não boto não, porque acho que fica feio. [ERI, 1, $80]$

b. $E[e u]_{i}$, infelizmente, e $\boldsymbol{u}_{\boldsymbol{i}}$ moro em área de risco. $[\mathrm{TAD}, 4,00]$

c. mas $[\mathrm{eu}]_{i}$, por mim, eu $\boldsymbol{u}_{i}$ acho que existe. [ALE, 1,80]

(24)a. [a pessoa $]_{i . . .}$ se a pessoa acha que aquilo ali é bom pra ela, então a pessoa $_{i}$ segue aquele seu destino [AND, 2,00]

b. $[E u]_{i}$ quando estou num grupo de amigo, eu $\boldsymbol{u}_{\boldsymbol{i}}$ só falo, sabe? [LEO, 2, 80]

Quanto à interrupção, exemplificada em (25), o comportamento foi equilibrado, apesar de o segundo período mostrar uma quantidade percentual ligeiramente maior de dados desse tipo.

\footnotetext{
${ }^{7} \mathrm{~A}$ interrupção se distingue da hesitação por apresentar material fonético diferente de hesitações e reformulações.

${ }^{8}$ Aqui foram considerados os advérbios, os sintagmas preposicionais e os sintagmas nominais com função adverbial.
} 


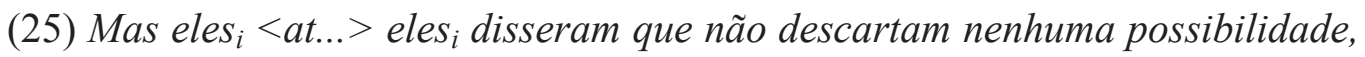
até de adoção. [EUC, 4,00$]$

No que diz respeito aos marcadores discursivos, observamos que foi a estrutura menos utilizada nas duas sincronias.

(26) a. [A minha mãe $]_{i}, \underline{\text { né}}$ El Ela $_{i}$ teve aneurisma $[\mathrm{ADR}, 2,00]$

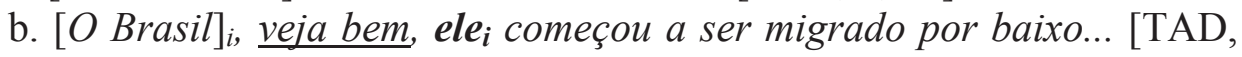
$4,00]$

Segundo Braga (1987), quanto mais distante o sujeito (aqui entendido como tópico) estiver do verbo, maior chance ele terá de aparecer retomado na sentença, ou seja, maior chance de ocorrer uma estrutura de DE sujeito. Para a autora, isso confirma a função do pronome correferente, que é a de "[...] lembrete da cabeça do SN sujeito que se agrega ao verbo e, enquanto tal, facilitador do processamento da informação..." (BRAGA, 1987, p.111).

Diante desses resultados, podemos colocar em discussão a hipótese de Braga (1987) de que a distância entre o núcleo do tópico e o verbo favorece a presença de retomada na sentença comentário. Encontramos uma ligeira superioridade de construções com material interveniente, porém sentenças sem esse tipo de material e sem elementos à direita do tópico (cf. resultados do grupo 'estrutura do tópico' nos mostram que DE sujeito também ocorre livremente quando o núcleo do tópico e o verbo estão próximos sem qualquer tipo de interrupção, confirmando os resultados de Avanzi (2011), que atestou, em análise prosódica, a não obrigatoriedade de pausa entre tópico e sentença comentário.

Assim como Braga (1987), Belford (2006) confirma a hipótese de que a presença de material interveniente entre o $\mathrm{SN}$ periférico (considerado nas referidas análises o "verdadeiro sujeito", que, na nossa análise é um tópico) e o predicado favorece a retomada pronominal. A autora afirma que o falante tem a preocupação de evitar qualquer falha na comunicação e, por isso, utiliza o pronome cópia como um lembrete do referente. Em sua análise de peso relativo, a autora encontra 0,91 para o uso de DE em relação à presença de material interveniente, contra apenas 0,09 para a ausência desse material, o que mostra um claro favorecimento de DE nesse contexto ${ }^{9}$.

Nossos resultados reforçam a ideia de que a presença do material interveniente é um importante grupo de fatores na retomada do SN transformando uma estrutura S V em Top S V. Entretanto, já temos evidências de que a construção de DE sujeito não é "motivada" pela distância (cf. ORSINI, 2003), já que existem línguas que não retomam o sujeito mesmo nesses contextos. No entanto, não se pode negar que, uma vez ocorrida a mudança na marcação do PSN, aumentam as ocorrências de DE sujeito no sistema do PB e fatores de natureza discursiva certamente atuam no uso dessa ferramenta. No francês, por exemplo, o uso de "moi, je" constitui uma importante estrutura na retomada de turno pelo falante, o que é feito numa Língua de Sujeito Nulo com um pronome fraco expresso.

\footnotetext{
${ }^{9}$ Lembremo-nos de que as autoras não trataram de estruturas com um pronome em posição de tópico.
} 
O último grupo a ser discutido é 'configuração sintática da estrutura em que ocorrem tópico e correferente'. O objetivo desse grupo é determinar em que contextos sintáticos aparecem as construções de DE sujeito. Com base na nossa hipótese de que o PB não tem restrições, é esperado que elas apareçam inclusive em contextos de subordinadas, diferenciando-se do PE que não licencia tal estrutura. A Tabela 5 mostra os resultados para esse grupo.

Tabela 5 Tipo de sentença em que ocorre a estrutura de DE

\begin{tabular}{|c|c|c|c|c|}
\hline & \multicolumn{2}{|c|}{ Anos 1980} & \multicolumn{2}{|c|}{ Ano 2000} \\
\hline & $\mathbf{N}^{0}$ oco & $\%$ & $\mathrm{~N}^{0}$ oco & $\%$ \\
\hline DE na sentença matriz & 166 & 79 & 116 & 80 \\
\hline DE na sentença encaixada & 30 & 14 & 16 & 11 \\
\hline Tópico e sujeito sem adjacência & 13 & 7 & 11 & 9 \\
\hline Total & 209 & 100 & 143 & 100 \\
\hline
\end{tabular}

Como já havia sido mostrado em trabalhos anteriores (cf. ORSINI, 2003), nossos resultados atestam que o contexto raiz é, de longe, o contexto preferido das construções de DE, nas duas sincronias, mais uma vez ilustrado em (27):

(27) [O Brasil] ${ }_{i}$ veja bem, ele $_{\boldsymbol{i}}$ começou a ser migrado por baixo. [TAD, 4, 00]

No entanto, embora em percentual mais baixo, as ocorrências de DE sujeito no interior de orações subordinadas (aqui tratados como DE na sentença encaixada) constituem um resultado muito importante para a nossa análise, pois, segundo Brito, Duarte e Matos (2003), "deslocamento à esquerda de tópico pendente" não ocorre em contextos encaixados no PE. ${ }^{10}$ Os exemplos em (28 a-b) mostram uma construção de DE também presente na amostra, em que o tópico ocorre dentro de uma subordinada completiva de verbo; em (28 c-d), vemos a ocorrência no interior de uma subordinada adverbial:

(28) a. Acho [que [ele $]_{i}$ primeiro ele e $_{\boldsymbol{i}}$ começou, assim.] [SAM, 2, 80]

b. acho [que [essa mudança] $]_{i}$ ela $\boldsymbol{a}_{i}$ não vem assim sem ninguém fazer nada] [PAU, 2, 80]

c. De preferência você não bota leite gelado nem quente, você bota em temperatura normal [porque [o leite gelado ou quente] ${ }_{i}$ ele pode assim- ele $\boldsymbol{e}_{\boldsymbol{i}}$ sola muito o bolo]. [DAV, 3, 80]

d. [se [uma professora $]_{i}$ ela [ $_{i}$ quer ter sucesso na sua profissão, (se) ela quer ser reconhecida como uma boa professora], ela vai ter que se aprimorar. [EVE, 3, 80]

Devemos mencionar ainda as construções em que tópico e o sujeito não estão adjacentes, já que o primeiro está na oração matriz e o segundo no interior da oração subordinada, como vemos em (29). Tal estrutura pode ocorrer em língua de sujeito nulo, como o português europeu e o espanhol (cf. RIVERO 1980 apud DUARTE, 1995 para o espanhol), mas o sujeito, em tais casos, recebe ênfase por estar numa construção com valor contrastivo. Não é o que se observa em (29). Os exemplos em (29a-b) foram produzidos por diferentes falantes, não se caracterizando por apresentar valor

\footnotetext{
${ }^{10}$ Note-se que as autoras se referem ao deslocamento de outros constituintes, já que a estrutura de DE sujeito não ocorre nas línguas de sujeito nulo.
} 
contrastivo. Em (29c), vemos um exemplo com o pronome "você", de referência arbitrária:

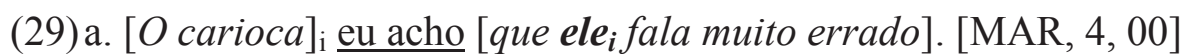

b. [O gaúcho $]_{\mathrm{i}}$, por exemplo, eu tenho impressão [de que eles $\boldsymbol{i}_{i}$ têm, assim, uma certa semelhança com o castelhano] [JAN, 4, 80]

c. quando cê pára de trabalhá / [você $]_{\mathrm{i}}$, eu senti isso, parece [que c $\hat{\boldsymbol{e}}_{i}$ vai emburrecê]. [EUC, 4, 00]

Esses resultados são, de fato, importantes: podemos dizer que a construção de DE sujeito no PB ocorre tanto em contexto raiz quanto em contexto encaixado. Há também construções em que o tópico se encontra na oração matriz e o correferente no interior da subordinada, não havendo, portanto, adjacência sintática. Registre-se também que essas construções não são marcadas no $\mathrm{PB}$, ou seja, não possuem valor contrastivo.

Outro grupo de fatores relevante para o estudo das construções de DE é a 'classe gramatical do correferente' e sua relação com a 'classe gramatical do tópico'. Não desenvolveremos essa análise aqui, porém observamos nos dados que a hipótese de que o PB não apresenta restrições para esse cruzamento, podendo o tópico (SN ou pronome) ser retomado tanto por um SN quanto por um pronome, independentemente de seu feixe de traços semânticos, é verdadeira. A retomada por pronome demonstrativo foi pouco frequente na amostra tanto nos anos 1980 quanto em 2000. O que constatamos foi que o tópico $\mathrm{SN}$, seja ele simples ou complexo, favorece uma retomada por outro $\mathrm{SN}$, enquanto tópico pronome favorece retomada por outro pronome. De maneira geral, retomada com pronome pessoal é a estratégia mais comum, seja o tópico um pronome ou um SN.

\section{CONSIDERAÇÕES FINAIS}

Nossa análise, que se ateve apenas a fatores linguísticos, revela informações importantes acerca dos dois períodos estudados. O tópico é predominantemente preenchido por pronome nos anos 1980, sendo a grande maioria pronomes de $1^{\mathrm{a}}$ pessoa. Em 2000, observamos uma mudança nessa representação, que pode estar relacionada a características particulares das entrevistas: o tópico passa a ser preferencialmente preenchido por um $\mathrm{SN}$, que não sofre restrições quanto ao traço semântico ou especificidade. No que diz respeito às retomadas, elas não parecem apresentar restrições, independentemente dos traços semânticos e do tipo do tópico. Encontramos leve preferência pela estrutura de DE sujeito em presença de elementos intervenientes, mas são expressivos percentualmente os dados de DE sem qualquer material interveniente, fato que sugere que a distância entre tópico e sujeito não é determinante para a ocorrência de DE. No que tange à configuração sintática da sentença em que ocorre DE sujeito, constatamos que, embora apareça mais frequentemente na sentença raiz, não há restrições ao aparecimento de $\mathrm{DE}$ em contextos encaixados, nem em contextos em que o tópico se encontra na oração matriz e o correferente, na subordinada, sem possuir valor contrastivo.

No que tange à comparação com outras línguas românicas, observamos que o PB tem um comportamento claramente diferente do $\mathrm{PE}$, do italiano e do espanhol que são 
línguas com proeminência de sujeito e não apresentam casos de DE sujeito como o PB. Nessas línguas, só temos DE sujeito em casos de não adjacência para ênfase.

Quanto ao francês, sistema que apresenta muitos casos de DE sujeito, sabemos que a construção com pronome forte "moi" de $1^{\mathrm{a}}$ pessoa é muito frequente (cf. BARNES, 1986). Nossos dados mostram que, no PB, esse tipo de estrutura foi muito recorrente nos anos 1980, porém apareceu menos na amostra de 2000, o que pode se dever, repetimos, a características da entrevista.

No que diz respeito às retomadas, no $\mathrm{PB}$, observamos que o pronome nominativo é a estratégia mais produtiva, independentemente do feixe de traços semânticos do tópico. A retomada com demonstrativo, muito produtiva no francês em casos de tópicos com o traço [-específico], não apresentou frequência relevante na nossa amostra em nenhum dos dois períodos. Na realidade, o demonstrativo é mais usado na escrita, evitando-se uma retomada pronominal. Contudo, é importante destacar que a restrição do francês, apresentada por Barnes (1986), de não licenciar tópicos [- animado] retomados por nominativos parece não existir mais. Reproduzimos aqui o exemplo do francês falado, que mostra um SN [- animado] sendo retomado por um nominativo assim como acontece no PB:

(30) [La croissance $]_{i}$, elle $\boldsymbol{e}_{\boldsymbol{i}}$ dépend de la confiance.

$\mathrm{O}$ crescimento, ele depende da confiança.

Quanto aos outros tipos de restrição, o PB se aproxima do francês, já que nossos tópicos podem introduzir informação nova no discurso sem função contrastiva ou entoação específica e as sentenças podem ocorrer em qualquer contexto sintático. Assim como no francês, as sentenças de DE sujeito aparecem majoritariamente em contexto matriz, porém elas também aparecem em contexto encaixado, ainda que em menor quantidade.

A preferência por SNs na posição de tópico, associada à ausência de restrições e às mudanças morfossintáticas pelas quais passa o sistema reforçam a aproximação do PB com as línguas mistas; línguas de tópico e sujeito na tipologia aqui utilizada (LI; THOMPSON, 1976). Nosso sistema se distancia, portanto, das línguas orientadas exclusivamente para o sujeito e o comportamento das estruturas descritas aqui pode ser tratados como evidência desse distanciamento.

Os resultados aqui encontrados corroboram os de autores como Duarte (1995), Orsini (2003), Vasco (2006), Vasco e Orsini (2007), que, a partir do trabalho de Pontes (1987), fizeram ampla descrição do conjunto das construções de tópico marcado no PB, o que lhes permitiu advogar em favor da inclusão do PB entre as línguas com proeminência de tópico e de sujeito. Nesta perspectiva, acreditamos que o presente trabalho, ao focalizar as construções de DE sujeito, fornece informações mais detalhadas acerca das características estruturais e contextuais dessas construções, contribuindo para a investigação do percurso da mudança paramétrica referente ao sujeito e seus reflexos no sistema gramatical do PB, além de suscitar outras investigações sobre o estatuto do sujeito e do tópico nas línguas com orientação parcial para o discurso. 


\section{REFERÊNCIAS}

AVANZI, M. La dislocation à gauche en français parlé. Etude instrumentale. Le français moderne $\mathrm{n}^{\circ} 2$. Neuchâtel \& de Paris Ouest Nanterre, 2011.

BARNES, B. K. An Empirical Study of the Syntax and Pragmatics of Left dislocations in Spoken French. In: JAEGGLI; SILVA-CORVALÁN (eds.) Studies in Romance Linguistics. Dordrecht: Foris, 1986. p. 207-224.

BELFORD, E. de M. Topicalização de objetos e deslocamento de sujeitos na fala carioca: um estudo sociolinguístico. Dissertação (Mestrado em Linguística). Universidade Federal do Rio de Janeiro, Rio de Janeiro, 2006.

BERLINCK, R. de A.; DUARTE, M. E. L.; OLIVEIRA, M. de. Predicação. In: KATO, M.; NASCIMENTO, M. do (orgs.). Gramática do português culto falado no Brasil: a construção da sentença. Vol. III. Campinas: Editora da UNICAMP, 2009. p. 101-188.

BRAGA, M. L. Esta dupla manifestação do sujeito, ela é condicionada linguisticamente. In: Anais do $34^{\circ}$ Seminário do GEL. Campinas, 1987. p. 106-115.

BRITO, A. M.; DUARTE, I.; MATOS, G. Estrutura da frase simples e tipos de frases. In: Mira Mateus et alii. Gramática da Língua Portuguesa. Lisboa: Caminho Ed, 2003 p. 433-506.

CHOMSKY, N. Lectures on Government and Binding. Dordrecht: Foris, 1981.

CYRINO, S., DUARTE, M. E., KATO, M. Visible subjects and invisible clitics in brazilian Portuguese In: KATO, M.A. e NEGRÃO, E.V. (orgs.) Brazilian Portuguese and the Null Subject Parameter. Madrid: Iberoamericana/ Frankfurt: Vervuert, 2000. p. 55-73.

DUARTE, M. E. L. Do pronome nulo ao pronome pleno: a trajetória do sujeito no português do Brasil. In: ROBERTS, I.; KATO, M. (org.). Português brasileiro: uma viagem diacrônica. Campinas: Editora Unicamp, 1993. p. 107-128.

- A perda do princípio "Evite Pronome" no português brasileiro. Tese (Doutorado), Instituto de Estudos da Linguagem/UNICAMP, Campinas, 1995.

. A evolução na representação do sujeito pronominal em dois tempos. In: $\overline{\text { PAIVA }}$, M. da C.; DUARTE, M. E. L. (org.). Mudança linguística em tempo real. Rio de Janeiro: Contra Capa / Faperj, 2003. p.115-128.

GALVES, C. C. A gramática do português brasileiro. In: Línguas e instrumentos linguísticos. Campinas: Pontes, nº 1 - Jan. / Jun 1998. P.79-96.

LABOV, W. Principles of linguistic change: internal factors. Oxford, Blackwell, 1994.

LI, C.-N.; THOMPSON, S. Subject and topic: a new typology of language. In: LI, C-N (ed.) Subject and Topic. New York: Academic Press, 1976. p. 457-489.

MARAFONI, R. L. A Distribuição do Objeto Nulo no Português Europeu e no Português Brasileiro. Tese (Doutorado). Faculdade de Letras, Universidade Federal do Rio de Janeiro. Rio de Janeiro, 2010.

MOLliCA, M. C.; BRAGA, M. L. (org.). Introdução à sociolinguística o tratamento da variação. São Paulo: Contexto, $3^{\mathrm{a}} \mathrm{Ed}, 2008$. 
ORSINI, M. T. As construções de tópico no português do Brasil: uma análise sintáticodiscursiva e prosódica. Tese (Doutorado). Faculdade de Letras, Universidade Federal do Rio de Janeiro. Rio de Janeiro, 2003.

; VASCO, S. L. Português do Brasil: língua de tópico e de sujeito. In: Diadorim - Revista de estudos linguísticos e literários. n 2. RJ: UFRJ, Programa de PósGraduação em Letras Vernáculas, 2007.

PAIVA, M. C. de; DUARTE, M. E. L. Mudança linguística: Observações no tempo real. In: MOLLICA, M. C.; BRAGA, M. L. (org.). Introdução à sociolinguística o tratamento da variação. São Paulo: Contexto, $3^{\mathrm{a}} \mathrm{Ed}, 2008$.

PONTES, E. O Tópico no Português do Brasil. Campinas: Ed. Pontes, 1987.

VASCO, S. L. Construções de tópico no português: as falas brasileira e portuguesa. Dissertação (Mestrado). Faculdade de Letras, Universidade Federal do Rio de Janeiro. Rio de Janeiro, 1999.

. Construções de tópico na fala popular. Tese (Doutorado). Faculdade de Letras, Universidade Federal do Rio de Janeiro. Rio de Janeiro, 2006.

WEINREICH, U.; LABOV, W.; HERZOG, M. Fundamentos empíricos para uma teoria da mudança linguística. [Tradução de Marcos Bagno]. São Paulo: Parábola Editorial, 2006.

Recebido: 30/05/2013

Aceito: 30/08/2013 